\title{
Small does not mean young: Age estimation of severely browsed trees in anthropogenic Mediterranean landscapes
}

\author{
Laurence Fazan $^{\mathrm{a}, \mathrm{b}}$, Markus Stoffel ${ }^{\mathrm{b}, \mathrm{c}}$, David J. Frey ${ }^{\mathrm{d}}$, Stergios Pirintsos ${ }^{\mathrm{e}, \mathrm{f}}$, Gregor Kozlowski d,g,* \\ ${ }^{a}$ Geography Unit, Department of Geosciences, University of Fribourg, Chemin du Musée 4, CH-1700 Fribourg, Switzerland \\ ${ }^{\mathrm{b}}$ Chair for Climatic Change and Climate Impacts, Institute for Environmental Sciences, University of Geneva, Route de Drize 7, CH-1227 Carouge, Switzerland \\ ${ }^{c}$ Laboratory of Dendrogeomorphology, Institute of Geological Sciences, University of Bern, Baltzerstrasse 1-3, CH-3012 Bern, Switzerland \\ ${ }^{\mathrm{d}}$ Department of Biology and Botanical Garden, University of Fribourg, Chemin du Musée 10, CH-1700 Fribourg, Switzerland \\ ${ }^{\mathrm{e}}$ Department of Biology, University of Crete, P.O. Box 2208, GR-71409 Heraklion, Crete, Greece \\ ${ }^{\mathrm{f}}$ Botanical Garden, University of Crete, Gallos Campus, GR-74100 Rethymnon, Crete, Greece \\ ${ }^{\mathrm{g}}$ Natural History Museum of Fribourg, Chemin du Musée 6, CH-1700 Fribourg, Switzerland
}

The knowledge of the age of individual trees and of population age structure is of great importance for conservation purposes. In Mediterranean areas, however, trees are rarely used for dendroecological studies as ring growth is strongly perturbed by browsing and other disturbances. This study focused on the Tertiary relict tree species Zelkova abelicea (Ulmaceae) endemic to the mountains of Crete (Greece) and searched for new approaches to estimate the age of threatened trees in severely browsed populations. Our results demonstrate that dwarfed $Z$. abelicea trees can attain ages $>500 \mathrm{yr}$ and that such individuals often surpass normally growing trees of the same population in number and age. These findings significantly change the perception of population age structure in forest remnants of Mediterranean landscapes. Additionally, we show that tree age is well correlated (64\%) with trunk circumference, for severely browsed dwarfed trees, however not so much (11\%) for normally developed, large trees. Thus, our results can be used directly for age estimations of severely dwarfed $Z$. abelicea individuals in the field and the new approach can be easily reproduced for other threatened tree species affected by strong browsing pressure. Future conservation efforts and management strategies should, therefore, take into account not only normally developed trees but also severely browsed individuals and their populations.

\section{Introduction}

On the Mediterranean island of Crete, agriculture and livestock breeding have existed for the past 10,000 $\mathrm{yr}$ (Cowling et al., 1996). However, browsing has occurred in this environment since the Pleistocene due to several large herbivores, and numerous plants have developed adaptations such as spines or cushion growth (Rackham and Moody, 1996). In combination with a drier climate and human pressure during the last millennia, a drastic reduction of the once widespread wooded areas and the formation of maquis or garigue can be observed, where trees often have dwarfed and bushy forms (Fielding and Turland, 2005).

* Corresponding author at: Department of Biology and Botanical Garden, University of Fribourg, Chemin du Musée 10, CH-1700 Fribourg, Switzerland. Tel.: +4126300 88 42; fax: +41263009740.

E-mail addresses: fazan0@etu.unige.ch (L. Fazan), markus.stoffel@dendrolab.ch (M. Stoffel), david.frey@unifr.ch (D.J. Frey), pirintsos@biology.uoc.gr (S. Pirintsos), gregor.kozlowski@unifr.ch (G. Kozlowski).
Nevertheless, the Mediterranean contains several refugial regions and is rich in relict plant species (Quézel and Médail, 2003). Among these, the Tertiary relict trees are of special interest, as they have been able to cope with changing environmental conditions for millions of years. However, modern-day representatives of genera such as Liquidambar, Platanus, Juglans, Pterocarya, Aesculus, and Zelkova, have only few natural and well-functioning populations, mainly in the eastern Mediterranean region - they should therefore be a conservation priority (Fineschi et al., 2002; Quézel and Médail, 2003).

The knowledge of the age of individual trees and of population age structure is of great importance for conservation purposes (Valladares and Sánchez-Gómez, 2006). Data on tree ages and ring-growth rates can be obtained with dendroecological methods. The most accurate results are usually obtained by destructive sampling (i.e. cutting down trees to count their increment rings), and are therefore not appropriate for threatened relict trees. Moreover, tree-ring analyses are not frequently performed on Mediterranean trees (Cherubini et al., 2003), primarily because browsing, along 
with other perturbations, often results in blurred environmental signals in the tree-ring record and disturbed ring formation (i.e. irregular growth, narrow or missing rings).

In this study, we used the Tertiary relict tree Zelkova abelicea (Ulmaceae), endemic to the mountains of Crete, Greece (Søndergaard and Egli, 2006), as a model organism to search for an approach to improve age estimates of threatened trees in heavily browsed populations with dwarfed individuals. The specific goals were (1) to determine the age of $Z$. abelicea individuals, including both normally growing and browsed, dwarfed trees; (2) to assess the relationship between tree age and circumference, and thus (3) to be able to predict the age of individual trees and the age structure of natural populations without using invasive sampling methods.

\section{Materials and methods}

\subsection{Study area and species information}

Crete is one of the major Mediterranean islands with a total area of $8729 \mathrm{~km}^{2}$ and has a landscape dominated by karstic mountain ranges (from west to east: Levka Ori, Ida Mountains, Dhikti Mountains and Thripiti Mountains; Supplementary Fig. S1) (Jahn and Schönfelder, 1995). Crete has a Mediterranean climate with hot and dry summers and cool and wet winters. Westerlies transport $1000-2000 \mathrm{~mm}$ of annual precipitation to the mountains, resulting in a precipitation gradient with larger total precipitation in the Levka Ori (west) than in the Thripiti Mountains (east) (Egli, 1997). Snowfall is not unusual in the mountains but only accumulates above $1400 \mathrm{~m}$ a.s.l., where it may persist until May (Rackham and Moody, 1996). Moisture from winter precipitation is partially stored in the soil throughout the summer (Egli, 1997). Over 1735 native plant species have been described on Crete, of which $\sim 10 \%$ are endemic to the island (Fielding and Turland, 2005).

Zelkova abelicea (Lam.) Boissier is a monoecious, broadleaved, ring-porous tree belonging to the elm family (Ulmaceae) (Denk and Grimm, 2005; Kozlowski et al., 2012). Z. abelicea was presumably widespread and likely formed a forest belt in the Cretan mountains in the past (Søndergaard and Egli, 2006). Nowadays, it occurs in scattered populations in the four mountain regions (Fig. S1) and is found growing between 900 and $1800 \mathrm{~m}$ a.s.l. Z. abelicea often grows in mixed stands with Acer sempervirens, Quercus coccifera and occasionally Cupressus sempervirens, on north-facing slopes, as well as in or around sinkholes where the water supply is most adequate and relatively constant and where soil conditions are most favorable (Egli, 1997; Søndergaard and Egli, 2006). Z. abelicea also grows in or around rocky river beds or gullies which are dry during summer but where humidity tends to remain in the subsurface and at high elevations $(>1500 \mathrm{~m}$ a.s.l.) on south-facing slopes.

The species is widely distributed in the Levka Ori Mountains and well represented in the Dhikti Mountains. In the Ida Mountains, only two populations occur nowadays: a large ( $>2000$ dwarfed and normally growing trees) and scattered one $\left(>20,500 \mathrm{~m}^{2}\right)$ on Mt. Kedros and a small ( $<800$ dwarfed and normally growing trees) and restricted one $\left(\sim 6670 \mathrm{~m}^{2}\right)$ on Mt. Psiloritis. A single population is known from the Thripiti Mountains (Fig. S1) (Egli, 1997).

Z. abelicea can be found as flowering, normally growing individuals with a crown, producing leaves $1.5-6 \mathrm{~cm}$ long as well as fruit. Shrubby, dwarfed individuals are also found, often with multiple stems, dense growth and leaves $<2 \mathrm{~cm}$, mainly due to browsing and presumably also water stress in some areas. Shrubby, dwarfed individuals are much more common than normally growing individuals and can form dense thickets in some areas. Seedlings are scarce and young plants have been reported to suffer from low survival rates (Egli, 1997). A precise description of the morphology and biology of the species can be found in Egli $(1995,1997)$ and Sarlis (1987).

Browsing represents a major threat to the sexual reproduction of the species as seedlings have little survival chances and browsed shrubs do not produce fruit. Fire also affects $Z$. abelicea, but shrubs have been seen to regenerate by suckering after fire disturbance (Søndergaard and Egli, 2006). In addition, altered water regimes resulting from the construction of reservoirs, land-use changes, road construction, and climatic changes, further affect the species populations. Soil erosion prevents seedlings from growing but aids the species' asexual perpetuation by exposing roots (personal observation).

\subsection{Sampling sites and dendroecological analyses}

The four mountain areas with Z. abelicea occurrences were sampled at 14 different sites so as to cover the entire distribution range of the species (Fig. S1 and Table S1). Samples were taken from 99 trees. In total, 186 increment cores and five crosssections were taken and sampled individuals were divided into three categories (Figs. S2-S4): (1) large, normally growing trees with a fully developed crown, with (potential) fruit production and having escaped browsing apart for the lowest branches; (2) an intermediate transitional category, grouping trees that could not be clearly categorized in one of the two other categories; and (3) small trees with a shrubby, dwarfed habit producing no fruit and being heavily browsed. Categories were called large, intermediate and small, respectively, and will be referred to as such from this point. The number of sampled trees per category and per sampling site is given in Table S1.

Ring widths were measured using a digital LINTAB 5 (resolution $1 \mu \mathrm{m}$ ) positioning table and TSAP-Win software (Rinntech, 2011). A mean annual ring-growth rate was calculated for each tree with the annual ring-width values of the cores.

\subsection{Age determination and statistical analyses}

Each tree was aged by dividing its trunk radius by its mean annual radial growth rate at breast height for large and intermediate trees and at the root collar (i.e. germination age) for small trees. Linear regressions were done and coefficients of determination $\left(R^{2}\right)$ were calculated to show the proportion of the age that is explained by the circumference. Moreover, Kruskal-Wallis and Mann-Whitney $U$ tests were performed to check similarity and significant differences, respectively, between the mean growth rates of large, intermediate and small trees.

\section{Results}

Tree-ring counting in large trees was usually straightforward and ring boundaries were easy to distinguish. This was not the case for intermediate nor, in particular, for small trees, in which very narrow and compact rings $(<0.2 \mathrm{~mm})$ were found, often reduced to one single row of vessels with intermitting tracheids, fibers and parenchyma cells. Annual ring growth rates could be determined successfully for 96 of the 99 trees selected for analysis (Tables 1 and S2). Growth rates differed greatly from one category to another and annual ring widths varied strongly in individuals with annual growth rates ranging from $<0.5$ to $>3 \mathrm{~mm}$ for some trees.

A few small and intermediate trees showed multiple piths (i.e. joining of several trunks) when observed under the microscope (Table S2) and their age might therefore have been overestimated in some cases. Trunk circumferences, radii, tree heights, mean 
Table 1

Mean growth rates, confidence limits ( $p=0.95$ ) and growth rate ranges (from minimal to maximal estimated growth rates) for large, intermediate, and small trees. Mean tree age, age range and number of aged trees per tree category are also included.

\begin{tabular}{|c|c|c|c|c|c|c|c|}
\hline $\begin{array}{l}\text { Tree } \\
\text { category }\end{array}$ & $\begin{array}{l}\text { Mean growth rate } \\
\left(\mathrm{mm} \mathrm{yr}^{-1}\right)\end{array}$ & $\begin{array}{l}\text { Confidence limits } \\
(p=0.95)\end{array}$ & $\begin{array}{l}\text { Growth rate range } \\
\left(\mathrm{mm} \mathrm{yr}^{-1}\right)\end{array}$ & $\begin{array}{l}\text { Standard deviation } \\
\left(\mathrm{mm} \mathrm{yr}^{-1}\right)\end{array}$ & $\begin{array}{l}\text { Mean tree } \\
\text { age (yr) }\end{array}$ & $\begin{array}{l}\text { Age range } \\
(\mathrm{yr})\end{array}$ & $\begin{array}{l}\text { Amount of aged trees } \\
(N=96)\end{array}$ \\
\hline Large & 1.235 & $0.965-1.505$ & $0.226-3.491$ & 0.728 & 129 & $27-514$ & 28 \\
\hline Intermediate & 0.395 & $0.321-0.469$ & $0.162-1.032$ & 0.186 & 148 & $29-373$ & 24 \\
\hline Small & 0.238 & $0.210-0.266$ & $0.126-0.489$ & 0.094 & 231 & $50-647$ & 44 \\
\hline
\end{tabular}

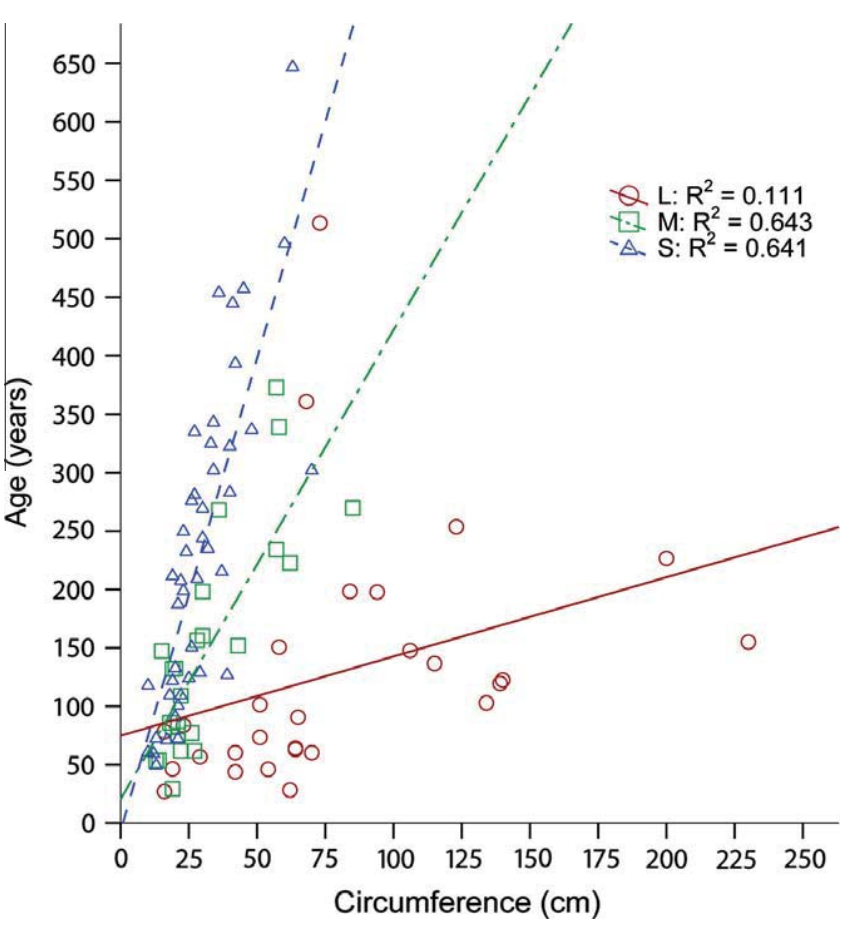

Fig. 1. Age and trunk circumference correlations for sampled trees. Circles, squares and triangles represent large (L), intermediate (M) and small (S) trees respectively. Linear regression lines and $R^{2}$ values are also given for each tree habit type.

annual ring growth rates and estimated ages are provided in Table S2.

The coefficient of determination $\left(R^{2}\right)$ is weak when performed for the entire sample $(n=96)$, with a value of 0.025 . Values of $0.111,0.643$, and 0.641 are obtained for large, intermediate and small trees, respectively. Age and circumference correlations for the three tree categories are represented in Fig. 1. Mean annual growth rates of large, intermediate and small trees differ significantly, as revealed by the Kruskal-Wallis test $\left(\chi^{2}=56.671\right.$, d.f. $=2, p<0.001)$. Mann-Whitney $U$ tests confirm these findings and indicate significant differences between the three tree categories when compared pairwise ( $p<0.001$, two-tailed).

\section{Discussion}

\subsection{Tree age: small does not mean young}

The prediction of age structure in populations of threatened species is fundamental for conservation purposes, in particular to estimate the proportion of (potentially) reproducing individuals (Hampe and Arroyo, 2002). Our study demonstrated that severely browsed $Z$. abelicea trees, whilst often remaining very small, can attain high ages ( $>500 \mathrm{yr}$ ) and greatly surpass in age large, normally growing neighboring trees. This phenomenon has not been demonstrated for Z. abelicea in previous studies (Søndergaard and Egli,
2006). Furthermore, it has rarely been perceived in browsed trees of the Mediterranean area (Gómez-Aparicio et al., 2005) and thus never taken into account for conservation practices.

Under extreme conditions, tree rings can be very compact and narrow, occasionally with unclear boundaries; in the worst case, they can even be partially or completely absent on the stem circumference. This problem has been observed in dwarfed trees with very slow growth (Villalba and Veblen, 1997). Missing rings have been reported in Mediterranean tree populations (Cherubini et al., 2003) in general and in Z. sicula (Garfi, 1997) in particular and have been shown to account for $\leqslant 10 \%$ of the total number of visible rings (Norton and Ogden, 1987). As a consequence, it seems likely that (partially) missing rings are an issue for $Z$. abelicea as well and that the real ages of small trees would be even higher. However, they are difficult to perceive in Z. abelicea, as only increment cores can be taken, not disk stems. Moreover, despite the limitations outlined above, the approach deployed in this study allowed an estimate of $Z$. abelicea ages, which is a useful addition to our knowledge and understanding of threatened Mediterranean tree species.

\subsection{Age-circumference correlations: the importance of tree habit}

Our study also demonstrated that increment rates of trees growing in anthropogenic Mediterranean landscapes are significantly different in dwarfed individuals in comparison to normally growing trees. Furthermore, age and circumference were strongly correlated for small and intermediate trees. The division of sampled trees into habit categories could easily be used for other tree species threatened by browsing or other disturbances. For Z $Z$. abelicea, the age-circumference correlations expressed in Fig. 1 allow an approximate age estimation of any browsed tree in the field and thus a rapid and simple determination of population age structure. This should significantly help any scientific study and in situ management and protection efforts for $Z$. abelicea.

In small and intermediate trees, the coefficient of determination is high ( 0.641 and 0.643 , respectively), and age seems to be highly correlated with circumference. This high correlation is likely reflective of (1) very slow tree growth, (2) the production of small rings and (3) very small fluctuations in inter-annual ring width in comparison to fluctuations in large trees (Table 1). One could also speculate that the small ring-width fluctuations observed in dwarfed trees could be caused by continuous browsing and exacerbated by repeated water stress.

In large trees, in contrast, the coefficient of determination is clearly lower (0.111). Differences in ring growth among large trees are presumably reflective of their different location (i.e. among several populations), where growth rates are not smoothed by browsing but primarily influenced by site conditions (precipitation, water stress, fire, erosion, etc.). These factors can greatly vary between the different sites investigated in this study.

\subsection{Old dwarfed trees: ignored potential for conservation?}

Trees are long living organisms, and the knowledge of their age and the maturity of individuals as well as the age structure of 
entire populations is of great importance, both for scientific studies and for practical in situ conservation efforts (Hampe and Arroyo, 2002; Plieninger et al., 2003; Villalba and Veblen, 1997b). The detection of high ages in dwarfed individuals of $Z$. abelicea is impressive as it indicates that individuals can survive under browsing pressure for centuries. Due to the very intensive vegetative reproduction of browsed trees (e.g. by suckering), the "genetic age" of such individuals might be even much higher. Therefore, dwarfed individuals of $Z$. abelicea and other threatened trees of the Mediterranean landscapes should be imperatively included into future conservation programs.

Furthermore, Fineschi et al. (2004) showed high genetic variation within populations of $Z$. abelicea from the Levka Ori, in contrast to $Z$. sicula from Sicily (which revealed to be represented by a unique genotype). This might indicate a high tolerance of $Z$. abelicea to disturbance. Moreover, our field surveys showed (Table S1) that dwarfed, browsed trees are probably not involved in gene flow, since only large trees flower, fruit, and reproduce sexually. Thus, old and severely browsed trees might differentiate genetically from large trees, and this could be of great importance for the conservation of genetic diversity in $Z$. abelicea. Further studies are required in this new direction, especially in estimating which part of the total genetic diversity of the species is conserved by old and dwarfed individuals.

\section{Conclusions}

Our study demonstrated that dwarfed and severely browsed trees of $Z$. abelicea can attain ages $>500 \mathrm{yr}$ and that they often surpass in number and age their normally growing counterparts. These findings significantly change our perception of population age structure in forest remnants of Mediterranean landscapes.

Moreover, we demonstrated that tree age is correlated with trunk circumference, especially for browsed trees. The results of this study can be applied directly to estimate the age of $Z$. abelicea individuals in the field, and this new approach can easily be reproduced for other threatened tree species affected by strong browsing pressure.

Finally, we conclude that the sexual reproduction of $Z$. abelicea is not a problem of age, apart for very young immature trees, but is mainly influenced by the level of browsing and other disturbances. Only normally growing, non-browsed trees are reproducing sexually. Future conservation efforts and management strategies will need to include both forest remnants with normally growing trees and populations composed of dwarfed, browsed individuals.

\section{Acknowledgments}

We acknowledge Yann Marbach for his help during fieldwork, Bernhard Egli for his valuable information, as well as Estelle Arbellay and Michelle Schneuwly-Bollschweiler for their assistance and advice during preparation, fieldwork and laboratory analyses. We are grateful to Richard B. Primack and anonymous reviewers for helpful comments on the manuscript. This study was done as part of the global action plan for the conservation of threatened Zelkova species done by the Botanic Garden of the University of Fribourg, Switzerland, in collaboration with Botanic Gardens Conservation
International (BGCI). Fieldwork was supported by the Franklinia Foundation and sampling permissions were granted by the Greek Ministry of the Environment (National Parks and Wildlife Management).

\section{Appendix A. Supplementary data}

Supplementary data associated with this article can be found, in the online version, at http://dx.doi.org/10.1016/j.biocon.2012. 04.026.

\section{References}

Cherubini, P., Gartner, B.L., Tognetti, R., Bräker, O.U., Schoch, W., Innes, J.L., 2003. Identification, measurement and interpretation of tree rings in woody species from Mediterranean climates. Biol. Rev. 78, 119-148.

Cowling, R.M., Rundel, P.W., Lamont, B.B., Kalin Arroyo, M., Arianoutsou, M., 1996. Plant diversity in Mediterranean-climate regions. TREE 11, 362-366.

Denk, T. Grimm, G.W. 2005. Phylogeny and biogeography of Zelkova (Ulmaceae sensu stricto) as inferred from leaf morphology, ITS sequence data and the fossil record. Bot. J. Linnean Soc. 147, 129-157.

Egli, B., 1995. Zelkova abelicea (Lam.) Boiss. In: Phitos, D., Strid, A., Snogerup, S., Greuter, W. (Eds.), The Red Data Book of rare and threatened plants of Greece. WWF, Athens, pp. 526-527.

Egli, B., 1997. A project for the preservation of Zelkova abelicea (Ulmaceae), a threatened endemic tree species from the mountains of Crete. Bocconea 5, 505510 .

Fielding, J., Turland, N., 2005. Flowers of Crete. Royal Botanic Gardens, Kew.

Fineschi, S., Anzidei, M., Cafasso, D., Cozzolino, S., Garfi, G., Pastorelli, R., Salvini, D., Taurchini, D., Vendramin, G.G., 2002. Molecular markers reveal a strong genetic differentiation between two European relic tree species: Zelkova abelicea (Lam.) Boissier and Z. sicula Di Pasquale, Garfi \& Quézel (Ulmaceae). Conserv. Genet. 3, $145-153$.

Fineschi, S., Cozzolino, S., Migliaccio, M., Vendramin, G.G., 2004. Genetic variation of relic tree species: the case of Mediterranean Zelkova abelicea (Lam.) Boissier and Z. sicula Di Pasquale, Garfi and Quézel (Ulmaceae). Forest Ecol. Manage. 197, 273-278

Garfi, G., 1997. Première contribution à l'étude de Zelkova sicula (Ulmaceae), une relique de la flore tertiaire, endémique de la Sicile sud-orientale. $\mathrm{PhD}$ thesis, University of Aix-Marseille III.

Gómez-Aparicio, L., Zamora, R., Gómez, J.M., 2005. The regeneration status of the endangered Acer opalus subsp. granatense throughout its geographical distribution in the Iberian Peninsula. Biol. Conserv. 121, 195-206.

Hampe, A., Arroyo, J., 2002. Recruitment and regeneration in populations of an endangered South Iberian Tertiary relict tree. Biol. Conserv. 107, 263-271.

Jahn, R., Schönfelder, P., 1995. Exkursionsflora für Kreta. Ulmer, Stuttgart.

Kozlowski, G., Gibbs, D., Huan, F., Frey, D., Gratzfeld, J., 2012. Conservation of threatened relict trees through living ex situ collections: lessons from the global survey of the genus Zelkova (Ulmaceae). Biodivers. Conserv. 21, 671-685.

Norton, D.A., Ogden, J., 1987. Dendrochronology: a review with emphasis on New Zealand applications. New Zealand J. Ecol. 10, 77-95.

Plieninger, T., Pulido, F.J., Konold, W., 2003. Effects of land-use history on size structure of holm oak stands in Spanish dehesas: implications for conservation and restoration. Environ. Conserv. 30, 61-70.

Quézel, P., Médail, F., 2003. Ecologie et biogéographie des forêts du bassin méditerranéen. Elsevier, Paris.

Rackham, O., Moody, J., 1996. The Making of the Cretan Landscape. Manchester University Press, Manchester.

Rinntech, 2011. TSAP-Win Scientific $\odot$, Version 0.53. <http://www.rinntech.com/ content/blogcategory/2/28/lang,english> (website consulted on 23.03.11).

Sarlis, G.P., 1987. Zelkova abelicea (Lam.) Boiss., an endemic species of Crete (Greece). Webbia 41 (2), 247-255.

Søndergaard, P., Egli, B., 2006. Zelkova abelicea (Ulmaceae) in Crete: floristics, ecology, propagation and threats. Wildenowia 36, 317-322.

Valladares, F., Sánchez-Gómez, D., 2006. Ecophysiological traits associated with drought in Mediterranean tree seedlings: individual responses versus interspecific trends in eleven species. Plant Biol. 8, 688-697.

Villalba, R., Veblen, T.T., 1997. Regional patterns of tree population age structures in northern Patagonia: climatic and disturbance influences. J. Ecol. 85, 113-124. 